\title{
Analysis of Bacterial Biofilm Formation in Patients with Malignancy Undergoing Double J Stent Indwelling and Its Influencing Factors
}

\author{
Ke Zeng ${ }^{1, *}$ \\ Jia-Mo Zhang ${ }^{2, *}$ \\ Xiao-Bin $\mathrm{Li}^{1}$ \\ Sheng-Xian Peng ${ }^{3}$ \\ Su-Chuan Zhang ${ }^{4}$ \\ Wen-Xian Xie ${ }^{5}$ \\ Chun-Fang $\mathrm{Xi}^{1}$ \\ Cheng-Jian $\mathrm{Cao}^{6}$ \\ 'Department of Urology, First People's \\ Hospital of Zigong City, Zigong, People's \\ Republic of China; ${ }^{2}$ Department of \\ Urology, YongChuan Hospital Chongqing \\ Medical University, Chongqing, People's \\ Republic of China; ${ }^{3}$ Scientific Research \\ Department, First People's Hospital of \\ Zigong City, Zigong, People's Republic of \\ China; ${ }^{4}$ Laboratory Department, First \\ People's Hospital of Zigong City, Zigong, \\ People's Republic of China; ${ }^{5}$ Department \\ of Basic Medicine, Sichuan Vocational \\ College of Health and Rehabilitation, \\ Zigong, People's Republic of China; \\ ${ }^{6}$ Zigong Academy of Medical Sciences, \\ First People's Hospital of Zigong City, \\ Zigong, People's Republic of China
}

*These authors contributed equally to this work
Objective: To analyze the bacterial biofilm (BF) formation in patients with malignancy undergoing double $\mathrm{J}$ stent indwelling and its influencing factors.

Methods: A total of 167 patients with malignant tumors who received double $\mathrm{J}$ stent indwelling in the hospital from January 2018 to January 2021 were included in the study. The urine and double $\mathrm{J}$ stent samples were collected for bacterial identification and observed for $\mathrm{BF}$ formation on the surface of the urinary catheter under a scanning electron microscope (SEM). Univariate and multivariate logistic regression analyses were used to analyze the influencing factors of BF.

Results: The BF formation rate was $34.73 \%$ (58/167). The BF formation rate of positive specimens cultured in urine and double $\mathrm{J}$ stent was significantly higher than that of negative ones $(P<0.05)$. Staphylococcus was the main BF bacteria in double $\mathrm{J}$ stent and urine culture specimens, followed by Enterococcus, Pseudomonas, Enterobacter, and Acinetobacter. Compared with the non-BF group, the number of viable bacteria in the double $\mathrm{J}$ stent and urine and the catheterization time in the BF group rose markedly $(P<0.05)$. Advanced age, chemotherapy, anemia, indwelling time $\geq 90 \mathrm{~d}$, and urinary tract infection were risk factors for $\mathrm{BF}$ formation in patients with malignancy undergoing double $\mathrm{J}$ stent indwelling $(P<0.05)$.

Conclusion: There is a high rate of BF formation in patients with malignancy undergoing double J stent indwelling, with Staphylococcus as the dominant species. Treatment requires enhanced urinary catheter management and nutritional status to inhibit BF formation and lower the rate of urinary catheter-related infections.

Keywords: malignant tumor, double J stent indwelling, biofilm, catheter-related infection, etiology, influence factor

\section{Introduction}

Double J ureteral stent, frequently used for indwelling ureter, can effectively relieve ureteral obstruction and prevent ureteral stenosis. ${ }^{1}$ Consequently, preoperative or intraoperative indwelling double $\mathrm{J}$ stent is a common measure to prevent ureteral injury $^{2}$ as well as postoperative upper urinary tract obstruction due to surgery or metastasis of tumor in patients with malignant tumors, especially gynecological and urinary malignant tumors. ${ }^{3}$ However, its therapeutic effect is undermined by complications, such as urinary tract infection and urinary sepsis in severe cases, which threatens the life and health of patients. ${ }^{4}$ It has been confirmed by relevant research that bacteria biofilm (BF) formation, membrane-like substances formed by bacteria adhering to the surface, can enable bacteria to develop drug resistance against
Correspondence: Cheng-jian Cao Zigong Academy of Medical Sciences, First People's Hospital of Zigong City, Zigong, People's Republic of China

Email cccji20II@I63.com 
antimicrobial agents. ${ }^{5}$ As a result, it is considered that the formation of BF may be a key contributory factor to the relapse and intractability of urinary tract infections. ${ }^{6}$ Therefore, the analysis of BF formation in patients with malignancy undergoing double $\mathrm{J}$ stent indwelling and the exploration of factors affecting urinary tract infection in patients are of great significance for clinical treatment. The results are reported as follows.

\section{Data and Methods}

\section{Clinical Data}

A total of 167 patients with malignant tumors who received double J stent indwelling in the hospital from January 2018 to January 2021 were included in the study. Inclusion criteria: (1) 18-80 years old; (2) malignant tumors confirmed by pathology; (3) the double J stent was indwelling for the first time, with the indwelling time no less than $30 \mathrm{~d}$; (4) COOK(UFH-626, USI-626-CE-B) double J stent was used; (5)Estimated survival time $\geq 6$ months. Exclusion criteria: (1) urinary tract infection existed before the double $\mathrm{J}$ stent indwelling; (2)double $\mathrm{J}$ stent indwelling contradiction; (3) failure in double J stent indwelling; (4)Infection occurred due to other reasons after operation; (5) urological tumors such as epithelial tumors of the upper urinary tract. The study was approved by the Hospital Ethics Committee of First people's hospital of Zigong city and the patients signed an informed consent form. The study was in accordance with the Helsinki Declaration as revised in 2013 for experiments involving humans.

\section{Methods}

\section{General Information Collection}

General information, including the patients' age, gender, height, weight, highest educational level, hypertension, diabetes mellitus, hormone therapy, chemotherapy, radiotherapy, tumor clinical stage, tumor type, anemia, double $\mathrm{J}$ stent indwelling time, the presence of urinary tract infection, and the type of urinary tract infection was recorded. Body Mass Index $(\mathrm{BMI})=$ Weight $(\mathrm{kg})$ divided by the square of Height (m).

\section{Specimen Collection}

After routine disinfection, draping, and local anesthesia, $3 \mathrm{~mL}$ of urine was collected by a disposable sterile syringe by urethral catheterization, and the double $\mathrm{J}$ stent was removed under a cystoscopy or ureteroscopy. The bladder pelvis segment was divided into two segments for observation, each about $3 \mathrm{~cm}$ long. One segment was observed under Scanning Electron Microscope (SEM) on the BF morphology on the surface of the double $\mathrm{J}$ stent. The other section of the double $\mathrm{J}$ tube was placed in the inoculation bottle, added with $30 \mathrm{~mL}$ of physiological saline, and eluted by the vortex shaker at $3000 \mathrm{R} / \mathrm{min}$ for 1 minute. Subsequently, the precipitate was inoculated into blood agar plate medium and MacConkey agar medium, and placed in a constant temperature incubator at $37^{\circ} \mathrm{C}$ for 16 to 24 hours. The formation of sterile colonies was observed, and the bacterial species and drug sensitivity were identified.

\section{Observation on BF Morphology on Double J Stent Surface and Counting of Viable Bacteria Colony}

In the groups of 30-60 days, 61-90 days, 91-120 days, 121-150 days, and more than 150 days, 5 specimens of double $\mathrm{J}$ stent were selected from each group by random number table method. The double $\mathrm{J}$ stent was rinsed with PBS solution three times, 10 min each. The samples were fixed with osmic acid for $1 \mathrm{~h}$ and rinsed with PBS solution three times, $10 \mathrm{~min}$ each. The dehydration was carried out in gradient with $30 \%, 50 \%, 70 \%, 80 \%$, $90 \%$, and $100 \%$ trimethyl methanol, respectively, and repeated for three times. After drying with a highvacuum coating apparatus for 20-30 min, the specimens of double J stent were scanned by a SEM (S3000N, Hitachi, Japan) after gold spraying, and six fields of $100 \mu \mathrm{m}$ were randomly selected for each specimen. The formation of BF on the surface of the double $\mathrm{J}$ stent was observed and photographed, and the viable bacterial colonies were counted. It is defined as BF if meeting the following morphological characteristics: water channel, three-dimensional structure, spherical or elliptical corpuscle coated with matrix.

\section{Viable Bacteria Counting and Bacterial Identification} $1 \mathrm{~mL}$ each of clean urine and double $\mathrm{J}$ stent rinsing fluid were collected, and viable bacteria counts were analyzed with a UF-1000i automatic urine analyzer from SYSMEX. Urine specimens and double J stent specimens were inoculated on blood agar plates (Zhengzhou Antu Company). All the specimens were identified in accordance with the national clinical inspection operating procedures. Vitek 2 compact automatic bacteria identification drug susceptibility instrument (Mérieux Company, France) was used to identify the bacteria, and the reagents were the matching GN, GP identification cards and GN13, GP67 drug susceptibility cards. ${ }^{7}$ 
Table I General Data of Malignant Tumor Patients with Indwelling Double J Stent $(n=167)$

\begin{tabular}{|c|c|c|}
\hline Item & Number of Cases & Ratio (\%) \\
\hline \multicolumn{3}{|l|}{ Age } \\
\hline$<60$ years old & 78 & 46.71 \\
\hline$\geq 60$ years old & 89 & 53.29 \\
\hline \multicolumn{3}{|l|}{ Gender } \\
\hline Male & 71 & 42.51 \\
\hline Female & 96 & 57.49 \\
\hline \multicolumn{3}{|l|}{ BMI } \\
\hline $18.5 \sim 22.9 \mathrm{kgm} 2$ & 57 & 34.13 \\
\hline $23.0 \sim 27.4 \mathrm{kgm} 2$ & 86 & 51.50 \\
\hline$\geq 27.5 \mathrm{kgm} 2$ & 24 & 14.37 \\
\hline \multicolumn{3}{|l|}{ Highest level of education } \\
\hline Junior secondary and below & 44 & 26.35 \\
\hline Senior high school and & 69 & 41.32 \\
\hline $\begin{array}{l}\text { technical Secondary school } \\
\text { College and above }\end{array}$ & 54 & 32.34 \\
\hline \multicolumn{3}{|l|}{ High blood pressure } \\
\hline Yes & 96 & 57.49 \\
\hline No & 71 & 42.51 \\
\hline \multicolumn{3}{|l|}{ Diabetes } \\
\hline Yes & 65 & 38.90 \\
\hline No & 102 & 61.10 \\
\hline \multicolumn{3}{|l|}{ Hormone therapy } \\
\hline Yes & 43 & 25.75 \\
\hline No & 124 & 74.25 \\
\hline \multicolumn{3}{|l|}{ Chemotherapy } \\
\hline Yes & 113 & 67.66 \\
\hline No & 54 & 32.34 \\
\hline \multicolumn{3}{|l|}{ Treat by radiation therapy } \\
\hline Yes & 56 & 33.53 \\
\hline No & 111 & 66.47 \\
\hline \multicolumn{3}{|l|}{ Clinical stages } \\
\hline I-II & 79 & 47.31 \\
\hline III-IV & 88 & 52.69 \\
\hline \multicolumn{3}{|l|}{ Malignant tumor type } \\
\hline Digestive system & 44 & 26.35 \\
\hline Urinary system & 62 & 37.13 \\
\hline Gynecology & 38 & 22.75 \\
\hline Others & 23 & 13.77 \\
\hline \multicolumn{3}{|l|}{ Anaemia } \\
\hline Yes & 63 & 37.72 \\
\hline No & 104 & 62.28 \\
\hline \multicolumn{3}{|l|}{ Stenting duration } \\
\hline $30 \sim 60 d$ & 21 & 12.57 \\
\hline
\end{tabular}

Table I (Continued).

\begin{tabular}{|l|c|c|}
\hline Item & Number of Cases & Ratio (\%) \\
\hline $61 \sim 90 \mathrm{~d}$ & 48 & 28.74 \\
$91 \sim 120 \mathrm{~d}$ & 56 & 33.53 \\
$121 \sim 150 \mathrm{~d}$ & 28 & 16.77 \\
$\geq 151 \mathrm{~d}$ & 14 & 8.38 \\
\hline
\end{tabular}

\section{Diagnosis Criteria ${ }^{8}$}

The occurrence of urinary infection within $48 \mathrm{~h}$ after indwelling or removal of double $\mathrm{J}$ stent was considered as urinary infection associated with double $\mathrm{J}$ stent. Urinary infection was diagnosed with urine bacterial culture containing Gram-positive cocci $\geq 104 \mathrm{CFU} / \mathrm{mL}$ and Gramnegative bacilli $\geq 105 \mathrm{CFU} / \mathrm{mL}$.

\section{Statistical Methods}

SPSS20.0 software was used for statistical analysis. Measurement data conforming to normal distribution were expressed as $(\overline{\mathrm{X}} \pm \mathrm{s})$. Independent sample $t$-test was used for comparison between groups, paired sample $t$-test for intragroup comparison, one-way analysis of variance for comparison among groups, and Sink-q test for pairwise comparison. The enumeration data were expressed by frequency or ratio and analyzed using the Karman non-correction method, with the total cases no less than 40 and the minimum theoretical frequency over 5 . Logistic regression was used to analyze the risk factors. $P<0.05$ indicated that the difference was statistically significant.

\section{Results}

\section{General Information About Double J Stent Indwelling Patients with Malignant Tumors}

Patients' general information is presented in Table 1.

\section{Formation of BF of Urine and Double J Stent Specimens}

The BF formation rate in 167 malignant tumor patients with double J stent indwelling was 34.73\% (58/167). Positive specimens cultured in urine and double $\mathrm{J}$ stent showed a remarkably higher formation rate of $\mathrm{BF}$ than those negative specimens $(P<0.05)$. See Table 2. 
Table 2 Formation of Urinary Stent BF in Double J Stent Indwelling Patients with Malignant Tumors

\begin{tabular}{|l|c|c|c|c|c|c|}
\hline \multirow{2}{*}{ Item } & Result & Number of Cases & \multicolumn{2}{|c|}{ BF Formation } & \multirow{2}{*}{$\chi^{2}$} \\
\cline { 3 - 6 } & & & Number of Cases & Formation Rate (\%) & \\
\hline \multirow{2}{*}{ Urine culture } & Positive & 45 & 11 & 24.4 & 12.01 & $<0.001$ \\
& Negative & 122 & 5 & 4.09 & \\
\hline Double J stent & Positive & 78 & 58 & 74.36 & 13.22 & $<0.001$ \\
culture & Negative & 89 & 3 & 3.37 & \\
\hline
\end{tabular}

\section{The Changes of Double J Tube Electron Microscope Monitoring of Patients in Each Group}

$\mathrm{BF}$ formation is observed on various surfaces. After 30 days, the bacteria on the surface of the double $J$ stent were few and scattered, and covered by a large number of fibrous membranes. Inconsistent amounts of inflammatory attachments and crystals were observed on the surface of the double J stent (Figure 1A). At 90 days, piles of colonies on the surface of the double $J$ stent were observed, and most were cocci (Figure 1B). The number of bacterial colonies in the ducts was $(1.73$ $\pm 0.59)$, (2.26 \pm 1.19$)$, (4. 68 \pm 1.31$),(5.71 \pm 1.06)$, (7.76 $\pm 1.37) \mathrm{CFU} / \mathrm{cm}^{2}$ in each group, respectively $(P<0.05)$. It shows that bacterial colonies, inflammatory attachments, crystals, and bacterial biofilm on the surface of the double $\mathrm{J}$ stent increase with the extend of the double $\mathrm{J}$ tube indwelling time.

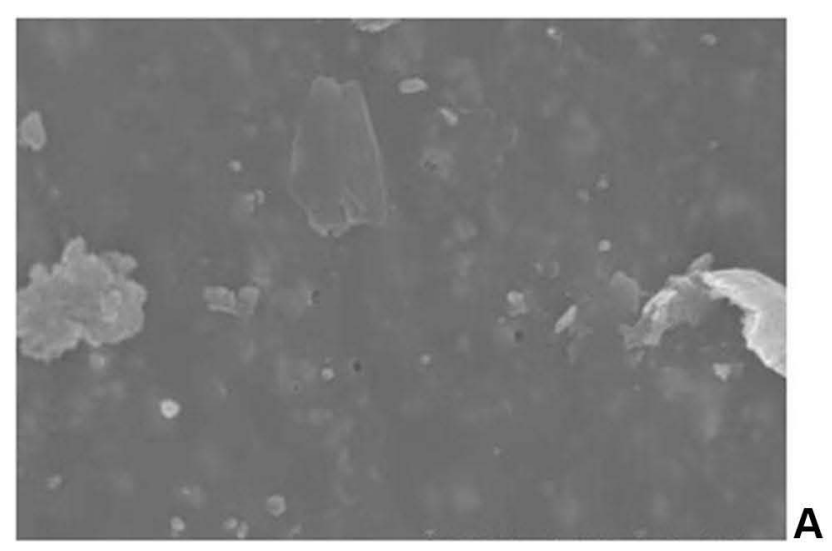

\section{Bacterial Identification of BF in Double J Stent of Patients}

A total of 58 strains of biofilm-positive bacteria were screened out from 78 positive specimens cultured in a double J stent. The results showed that Staphylococcus was the main type of bacteria in double $\mathrm{J}$ stent, followed by Enterococcus, Pseudomonas, Enterobacter, and Acinetobacter. See Table 3.

\section{Bacterial Identification of BF in the Urine of Patients}

Eleven strains of biofilm-positive bacteria were screened out from 45 positive urine-cultured specimens. After identifying the bacterial genus, it was found that the biofilm bacteria in the urine were mainly Staphylococcus, followed by Enterococcus, Pseudomonas, and Enterobacter, Acinetobacter, see Table 4.

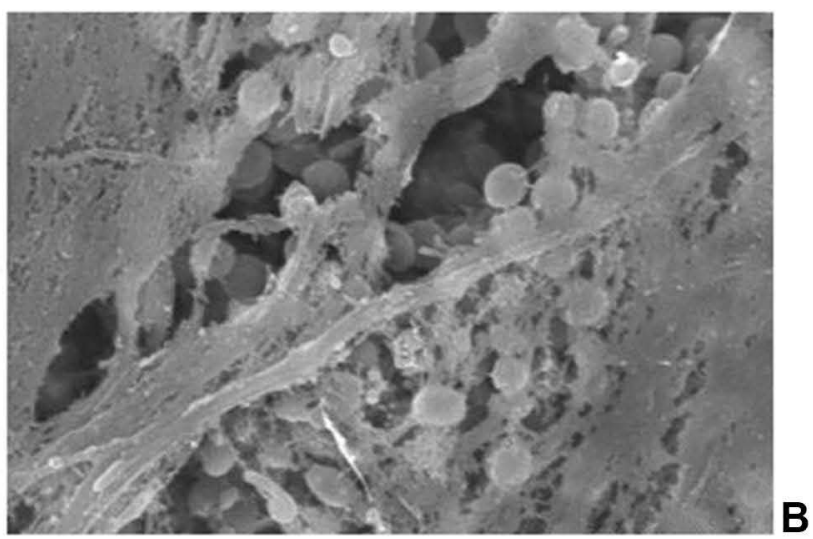

Figure I BF morphology on the surface of double J (SEM, $\times 600)$.

Notes: (A) no BF formation. SEM shows normal grooves and depressions, no adhesions on the surface; (B) BF formation. SEM shows the presence of polymorphism in the inner wall of the ureter, partly with single or multiple bacterial adhesions, and visible stereospecific structure formation. 
Table 3 Bacterial Identification of BF in Double J Stent of Patients

\begin{tabular}{|l|c|c|c|}
\hline Strain & Bacterial Name & Number of Plants & Ratio (\%) \\
\hline Enterobacter hormaeche and edwards & Escherichia coli & 6 & 10.34 \\
Enterococcus & Enterococcus faecalis & 14 & 24.14 \\
& Uroenterococcus & 5 & 8.62 \\
\hline Pseudomonas & Pseudomonas aeruginosa & 5 & 8.62 \\
Staphylococcus & Staphylococcus epidermidis & 11 & 18.97 \\
& Staphylococcus haemolyticus & 7 & 12.07 \\
& Staphylococcus aureus & 6.34 \\
Acinetobacter & Acinetobacter baumannii & 6 & 10.34 \\
Total & & 58 & 100.00 \\
\hline
\end{tabular}

Table 4 Bacterial Identification of Urine BF in Patients

\begin{tabular}{|l|c|c|c|}
\hline Strain & Bacterial Name & Number of Plants & Ratio \\
\hline Enterobacter hormaeche and edwards & Escherichia coli & 6 & 15.38 \\
Enterococcus & Enterococcus faecalis & 16 & 41.03 \\
& Uroenterococcus & 1 & 2.56 \\
\hline Pseudomonas & Pseudomonas aeruginosa & 1 & 2.56 \\
Staphylococcus & Staphylococcus epidermidis & 6 & 15.38 \\
& Staphylococcus haemolyticus & 4 & 10.26 \\
& Staphylococcus aureus & 3 & 7.69 \\
Acinetobacter & Acinetobacter baumannii & 2 & 5.13 \\
Total & & 39 & 100.00 \\
\hline
\end{tabular}

\section{Comparison of Viable Counts of Bacteria} - In Double J Stent and Urine of Patients in the BF-Forming Group and Non-BF-

\section{Forming Group}

The viable count of bacteria in the double $J$ stent and urine of patients of the BF-forming group exceeded that of the non-BF-forming group $(P<0.05)$. See Table 5 .

Table 5 Comparison of Viable Counts of BF in Double J Stent and in Urine of Patients Between the BF Forming Group and the Non BF Forming Group (Cells $/ \mu \mathrm{L}, \bar{X} \mathrm{~s}$ )

\begin{tabular}{|l|c|c|c|}
\hline Group & $\begin{array}{c}\text { Number of } \\
\text { Cases }\end{array}$ & $\begin{array}{c}\text { Double } \\
\text { J Stent }\end{array}$ & Urine \\
\hline BF forming group & 58 & $\begin{array}{r}1042.54 \\
\pm 253.46\end{array}$ & $\begin{array}{c}836.48 \\
\pm 214.32\end{array}$ \\
\hline Non BF forming & 109 & $\begin{array}{c}234.28 \\
\pm 248.14\end{array}$ & $\begin{array}{r}\mid \mathrm{II} 2.36 \\
\pm 123.6 \mathrm{I}\end{array}$ \\
group & & 19.893 & $27.70 \mathrm{I}$ \\
\hline$t$ & & $<0.00 \mathrm{I}$ & $<0.00 \mathrm{I}$ \\
\hline$P$
\end{tabular}

Comparison of Double J Stent Indwelling Time Between Groups with and without BF Formation

A markedly longer double $\mathrm{J}$ stent indwelling time was recorded with patients in the BF-forming group in comparison with the non-BF-forming group $(P<0.05)$. See Table 6.

Table 6 Comparison of Double J Stent Time of Patients in the BF Forming Group and Non BF Forming Group (d, $\bar{X} \mathrm{~s}$ )

\begin{tabular}{|l|c|c|}
\hline Group & $\begin{array}{c}\text { Number of } \\
\text { Cases }\end{array}$ & $\begin{array}{c}\text { Stent Setting } \\
\text { Time }\end{array}$ \\
\hline BF forming group & 58 & $18.93 \pm 2.48$ \\
\hline $\begin{array}{l}\text { Non BF forming } \\
\text { group }\end{array}$ & 109 & $8.14 \pm 2.31$ \\
\hline$t$ & & 28.011 \\
\hline$P$ & & $<0.001$ \\
\hline
\end{tabular}


Table 7 Comparison of Viable Counts of Biofilm in Double J Stent and Urine of Patients with Different Double J Stent Duration (Cells/ $\mu \mathrm{L}, \bar{X} \mathrm{~s}$ )

\begin{tabular}{|l|c|c|c|}
\hline $\begin{array}{l}\text { Tube Setting } \\
\text { Time }\end{array}$ & $\begin{array}{c}\text { Number of } \\
\text { Cases }\end{array}$ & $\begin{array}{c}\text { Double } \\
\text { J Stent }\end{array}$ & Urine \\
\hline 30 60d & 21 & $\begin{array}{c}349.61 \\
\pm 187.43\end{array}$ & $\begin{array}{r}138.49 \\
\pm 84.36\end{array}$ \\
\hline 6I 90d & 48 & $\begin{array}{r}512.43 \\
\pm 195.82\end{array}$ & $\begin{array}{c}298.69 \\
\pm 80.41\end{array}$ \\
\hline 91 120d & 56 & 739.48 & 412.43 \\
& & \pm 198.84 & \pm 78.95 \\
\hline I2I 150d & 28 & 993.16 & 647.15 \\
& & \pm 201.15 & \pm 81.47 \\
\hline I15Id & 14 & 1134.14 & 834.18 \\
& & \pm 214.36 & \pm 85.64 \\
\hline F & & 59.767 & 236.852 \\
$P$ & & $<0.001$ & $<0.001$ \\
\hline
\end{tabular}

Comparison of Viable Counts Of Bacteria in Double J Stent and Urine of Patients with Different Double J Stent Indwelling

\section{Time}

As the stenting duration increased, the viable count of bacteria in the double $\mathrm{J}$ stent and urine grew significantly $(P<0.05)$. See Table 7 .

\section{Analysis of the Influencing Factors BF Formation in Malignant Tumor Patients with Double J Stent Indwelling}

Patients with an age of $\geq 60$ years, female, diabetes, hormonal therapy, chemotherapy, anemia, long duration of tube indwelling, and urinary tract infection had significantly increased rates of ureteral BF formation $(P<0.05)$. See Table 8 .

\section{Logistic Regression Analysis for Multiple Factors of Urinary Catheter BF Formation in Malignant Tumor Patients with Double J Stent Indwelling}

Advanced age, chemotherapy, anemia, indwelling time $\geq 90 \mathrm{~d}$, and urinary tract infection were risk factors for $\mathrm{BF}$ formation in patients with malignancy undergoing double $J$ stent indwelling $(\mathrm{P}<0.05)$. See Table 9 .

\section{Discussion}

Indwelling double $\mathrm{J}$ stent is a significant step to prevent upper urinary tract obstruction after malignant tumor surgery to achieve better quality of life. ${ }^{9}$ Relevant evidence suggests that the rate of catheter-associated urinary tract infections remains at a high level in recent years, which requires sufficient attention. ${ }^{10}$ The application of double $\mathrm{J}$ stent mainly plays a role in fixedly supporting the ureter, relieving the obstruction caused by ureteral edema and inflammation, and preventing postoperative anastomotic leakage and ureteral stenosis, ${ }^{11}$ which ensures a shorter bed rest and a better rehabilitation effect with no limitation and discomfort from the external drainage stent. ${ }^{12}$ However, it has been found that the presence of double $\mathrm{J}$ stent predisposes to urinary reflux in the ureter, resulting in a rise in the retrograde infection rate of the kidney. ${ }^{13}$ Zhou Honghui et $\mathrm{al}^{14}$ reported that the rate of urinary tract infection in patients with double $\mathrm{J}$ stent indwelling for early radical cervical cancer was about $22.95 \%$. The rate of BF formation in this study $(34.73 \%)$ was slightly higher than that reported by others ${ }^{14}$ and was related to the inclusion of gastrointestinal and urinary malignancies in this study. The high molecular materials such as polyurethane used in the double $\mathrm{J}$ stent facilitate the adherence of bacteria to its surface and the subsequent formation of BF. Prior research demonstrated that the formation of bacterial BF can increase its resistance by more than 1000 times $^{15}$ and inhibit its antigenic expression to generate immune escape. ${ }^{16}$ In addition, under appropriate conditions, the bacteria in $\mathrm{BF}$ can diffuse and free from the membrane, causing re-infection. ${ }^{17}$

In this study, urine and double $\mathrm{J}$ stent specimens were collected from patients, respectively, and SEM observation revealed that $\mathrm{BF}$ formation was found in 39 of 45 positive urine culture specimens, which was consistent with the results of previous studies, and $\mathrm{BF}$ formation was found in 13 other negative urine culture specimens, which may be related to the fact that urine bacteria are mostly planktonic, thereby leading to false-negative results; however, the influence of native bacteria on the results was not excluded, which requires further analysis. ${ }^{18}$ Moreover, BF formation was found in 58 of 78 positive double $\mathrm{J}$ stent culture specimens, and no BF formation was found in negative double $\mathrm{J}$ stent culture specimens. These results suggest that the rate of $\mathrm{BF}$ formation is higher in patients with malignancy undergoing double $\mathrm{J}$ stent indwelling, and double $\mathrm{J}$ stent culture more 
Table 8 Analysis of Urinary Catheter BF Formation in Malignant Tumor Patients with Double J Stent Indwelling

\begin{tabular}{|c|c|c|c|c|c|}
\hline Item & Number of Cases & BF Forming Group $(n=58)$ & Non BF Forming Group $(n=109)$ & $t \chi^{2}$ & $P$ \\
\hline Age & & & & 18.184 & $<0.001$ \\
\hline$<60$ years old & 78 & 14 & 64 & & \\
\hline$\geq 60$ years old & 89 & 44 & 45 & & \\
\hline Gender & & & & 6.340 & 0.012 \\
\hline Male & 71 & 17 & 54 & & \\
\hline Female & 96 & 41 & 55 & & \\
\hline BMI & & & & 5.154 & 0.076 \\
\hline $18.5 \sim 22.9 \mathrm{kgm} 2$ & 57 & 16 & 41 & & \\
\hline $23.0 \sim 27.4 \mathrm{kgm} 2$ & 86 & 29 & 57 & & \\
\hline$\geq 27.5 \mathrm{kgm} 2$ & 24 & 13 & II & & \\
\hline Highest level of education & & & & 0.372 & 0.830 \\
\hline Junior secondary and below & 44 & 16 & 28 & & \\
\hline Senior high school and & 69 & 25 & 44 & & \\
\hline technical secondary school & & & & & \\
\hline College and above & 54 & 17 & 37 & & \\
\hline High blood pressure & & & & 0.297 & 0.586 \\
\hline Yes & 96 & 35 & 61 & & \\
\hline No & 71 & 23 & 48 & & \\
\hline Diabetes & & & & 21.120 & $<0.001$ \\
\hline Yes & 65 & 38 & 27 & & \\
\hline No & 102 & 21 & 81 & & \\
\hline Hormone therapy & & & & 40.240 & $<0.001$ \\
\hline Yes & 43 & 32 & 11 & & \\
\hline No & 124 & 26 & 98 & & \\
\hline Chemotherapy & & & & 11.488 & 0.001 \\
\hline Yes & 113 & 49 & 64 & & \\
\hline No & 54 & 9 & 45 & & \\
\hline Treat by radiation therapy & & & & 0.036 & 0.850 \\
\hline Yes & 56 & 20 & 36 & & \\
\hline No & 111 & 38 & 73 & & \\
\hline Clinical stages & & & & 0.629 & 0.428 \\
\hline I-II & 79 & 25 & 54 & & \\
\hline III-IV & 88 & 33 & 55 & & \\
\hline Malignant tumor type & & & & 1.207 & 0.751 \\
\hline Digestive system & 44 & 16 & 28 & & \\
\hline Urinary system & 62 & 21 & 41 & & \\
\hline Gynecology & 38 & 15 & 23 & & \\
\hline Others & 23 & 6 & 17 & & \\
\hline Anemia & & & & 65.413 & $<0.001$ \\
\hline Yes & 63 & 46 & 17 & & \\
\hline No & 104 & 12 & 92 & & \\
\hline Stent setting time & & & & 51.817 & $<0.001$ \\
\hline $30 \sim 60 d$ & 21 & 4 & 17 & & \\
\hline
\end{tabular}

(Continued) 
Table 8 (Continued).

\begin{tabular}{|c|c|c|c|c|c|}
\hline Item & Number of Cases & BF Forming Group $(n=58)$ & Non BF Forming Group $(n=109)$ & $t \chi^{2}$ & $\mathbf{P}$ \\
\hline $61 \sim 90 d$ & 48 & 5 & 43 & & \\
\hline $91 \sim 120 d$ & 56 & 16 & 40 & & \\
\hline$|2| \sim 150 d$ & 28 & 21 & 7 & & \\
\hline$\geq 151 d$ & 14 & 12 & 2 & & \\
\hline Urinary tract infection & & & & 38.498 & $<0.001$ \\
\hline Yes & 45 & II & 34 & & \\
\hline No & 122 & 5 & 117 & & \\
\hline Type of urinary tract infection & & & & 22.474 & 0.215 \\
\hline Symptomatic & 21 & 14 & 7 & & \\
\hline Asymptomatic & 24 & 13 & 11 & & \\
\hline
\end{tabular}

accurately responds to bacterial colonization and BF formation in the urinary catheter than urine culture. The results of bacterial identification showed that Staphylococcus was the dominant type of bacteria in the double $\mathrm{J}$ stent and urine culture samples, followed by Enterococcus, Pseudomonas, Enterobacter, and Acinetobacter, which was basically in line with the previous research results. ${ }^{8,14}$ This suggested that, compared with other types of bacteria, Staphylococcus might be more prone to produce biofilm bacteria, which provides a reference for the selection of clinical antibacterial drugs.

Moreover, this study found that the viable count of bacteria in both double $\mathrm{J}$ stent and urine rose sharply with the increase of stenting duration, indicating that the risk of $\mathrm{BF}$ formation grew with the increase of stenting duration, which was confirmed by the results of electron microscope scan. In clinical practice, the application of indwelling double $\mathrm{J}$ stent requires strict management to reduce unnecessary use. To reduce the formation of $\mathrm{BF}$, Double J stent requires regular replacement or the periodical evaluation of double $J$ stent removal in a timely manner. Analysis of factors influencing the formation of BF in the urinary catheter in patients with malignancy undergoing double $\mathrm{J}$ stent indwelling found that patients with an age of $\geq 60$ years, female, diabetes, hormonal therapy, chemotherapy, anemia, long duration of tube indwelling, and urinary tract infection had significantly increased rates of ureteral BF formation, and advanced age, chemotherapy, anemia, indwelling time $\geq 90 \mathrm{~d}$, and urinary tract infection were risk factors for BF formation in patients with malignancy undergoing double $\mathrm{J}$ stent indwelling. It indicated that enhanced nutritional management for elderly patients, urethral care for female patients, and strict control of blood glucose levels in diabetic patients are warranted to reduce the rate of urinary catheter-related infections.

In conclusion, there is a high rate of $\mathrm{BF}$ formation in patients with malignancy undergoing double $\mathrm{J}$ stent indwelling, with Staphylococcus as the dominant species. Treatment requires enhanced urinary catheter management and nutritional status to inhibit BF formation and lower the rate of urinary catheter-related infections. The shortcoming of this study lies in the absence of characterization analysis of the isolates, ${ }^{19}$ which limits the determination of treatment protocols and will be explored in further studies.

Table 9 Multi-Factor Logistic Regression Analysis of Urinary Catheter BF Formation in Malignant Tumor Patients with Double J Stent Indwelling

\begin{tabular}{|l|c|c|c|c|c|}
\hline Factor & $\boldsymbol{\beta}$ & SE & Wald & $\boldsymbol{P}$ & OR (95\% CI) \\
\hline Age $\geq 60$ years old & 1.123 & 0.487 & 5.364 & 0.012 & $3.236(1.198 \sim 7.456)$ \\
Chemotherapy & 1.012 & 0.326 & 4.264 & $<0.00 \mathrm{I}$ & $3.697(2.342 \sim 6.397)$ \\
Anaemia & 1.214 & 0.418 & 6.978 & $<0.00 \mathrm{I}$ & $3.523(2.971 \sim 7.448)$ \\
Catheter time 90 d or higher & 1.435 & 0.523 & 11.751 & $<0.00 \mathrm{I}$ & $5.044(1.893 \sim 11.784)$ \\
Urinary tract infection & 1.237 & 0.272 & 8.233 & $<0.00 \mathrm{I}$ & $3.912(\mathrm{I} .292 \sim 8.396)$ \\
\hline
\end{tabular}




\section{Disclosure}

The authors report no conflicts of interest in this work.

\section{References}

1. Sundaramurthy S, Thomas RJ, Herle K, et al. Double J stent removal in paediatric patients by Vellore Catheter Snare technique: a randomised control trial. J Pediatr Urol. 2019;15(6):661-668. doi:10.1016/j.jpurol.2019.08.009

2. Haitao Y, Wei Z, Chunhong N. Comparison and analysis of ureteral stricture caused by malignant tumor treated by conventional surgery and minimally invasive double $\mathrm{J}$ stent retrograde insertion. Chin Basic Med. 2021;28(2):203-207.

3. He JW, Shu G, Songtao X, et al. Analysis of clinical data of 96 cases of ureteral obstruction caused by gynecological malignant tumor. Chin $J$ Endoscopy. 2020;26(2):65-69.

4. Dengjun H, Yong L, Chan A, et al. Effect of pre-set double J stents on complications of flexible ureteroscopic lithotripsy in kidney calculi. Med J Qilu. 2017;155(5):87-89.

5. Rajput A, Thakur A, Sharma S, et al. aBiofilm: a resource of anti-biofilm agents and their potential implications in targeting antibiotic drug resistance. Nucleic Acids Res. 2018;46(D1):894-900. doi:10.1093/nar/gkx1157

6. Betschart P, Zumstein V, Buhmann MT, et al. Symptoms associated with long-term double-J ureteral stenting and influence of biofilms. Urology. 2019;134(4):72-78. doi:10.1016/j.urology.2019.08.028

7. Hong S, Yushan W, Ziyu S. National operating procedures for clinical examination. People's Health Publishing House; 2015.

8. Yuncai Y, Junlin Z, Jianming C. Characteristics and drug resistance of pathogens causing catheter-related urinary tract infection. Chin $J$ Disinfect. 2017;34(10):986-988.

9. AI-ling Z, Qiong-feng X, Fang-lei X, et al. Analysis of influencing factors of time of indwelling catheter for patients with benign prostatic hyperplasia and malignant tumor after operation. Chin J Mod Nurs. 2017;23(13):1718-1723.
10. Mingrong S, Wenzhi H, Quanhui W. Investigation on prevalence rate of catheter-related urinary tract infection from 2012 to 2018. Chin J Nosocomiol. 2020;30(15):91-95.

11. Alnadhari I, Alwan MA, Salah MA, et al. Treatment of retained encrusted ureteral double-J stent. Arch Ital Urol Androl. 2019;90 (4):265-269. doi:10.4081/aiua.2018.4.265

12. Wuxue LI, Zhao X, Changbao XU, et al. Clinical observation of time of double $\mathrm{J}$ stent indwelling in treatment of complex ureteral calculi with ureteroscope. J Pract Med. 2017;33(2):256-258.

13. Shi ZJ, Qiong Z, Lixin J, et al. Analysis of clinical characteristics of double J stent urinary system infection. J Wuhan Univ. 2020;41(3):109-113.

14. Zhou HH, Wang N, Ding JJ. Etiological characteristics and influencing factors of urinary tract infection in patients with double $\mathrm{J}$ stents indwelling in radical hysterectomy for early cervical cancer. Chin J Nosocomiol. 2019;29(18):2839-2842.

15. Goswami S, Sarkar R, Saha P, et al. Effect of human placental extract in the management of biofilm mediated drug resistance - A focus on wound management. Microb Pathog. 2017;111(34):307-315. doi:10.1016/j.micpath.2017.08.041

16. Jia L, Sun L, Wei L, et al. A nuclease from Streptococcus mutans facilitates biofilm dispersal and escape from killing by neutrophil extracellular traps. Front Cell Infect Microbiol. 2017;28(7):97-99.

17. Heim CE, Bosch ME, Yamada KJ, et al. Lactate production by Staphylococcus aureus biofilm inhibits HDAC11 to reprogramme the host immune response during persistent infection. Nat Microbiol. 2020;5(10):1271-1284. doi:10.1038/s41564-020-0756-3

18. Zhang JZ. Exploration on related factors and preventive measures of indwelling urethral catheterization in urinary system infection of hospital. Contemp Med. 2017;23(6):116-117.

19. Gajdács M, Kárpáti K, Stájer A, et al. Insights on carbapenem-resistant Pseudomonas aeruginosa: phenotypic characterization of relevant isolates. Acta Biologica Szegediensis. 2021;65 (1):105-112. doi:10.14232/abs.2021.1.105-112
Infection and Drug Resistance

\section{Publish your work in this journal}

Infection and Drug Resistance is an international, peer-reviewed openaccess journal that focuses on the optimal treatment of infection (bacterial, fungal and viral) and the development and institution of preventive strategies to minimize the development and spread of resistance. The journal is specifically concerned with the epidemiology of antibiotic resistance and the mechanisms of resistance development and diffusion in both hospitals and the community. The manuscript management system is completely online and includes a very quick and fair peerreview system, which is all easy to use. Visit http://www.dovepress.com/ testimonials.php to read real quotes from published authors. 